\title{
Anthropological futures for the study of cultural resilience of 'Western' North American societies in the face of climate change
}

\author{
by Megan Paranich
}

Climate change, as a scientifically defined global phenomenon, threatens the cultural resiliency of societies the world over. Anthropology has accrued a rich body of ethnographic research that has illuminated the potential of cultural resiliency for indigenous and nonWestern societies. This information is vital for understanding the political, social, and economic movement of these societies. However, the same research focus and academic rigor has not been applied to non-indigenous, Western societies. These societies have been examined for economic and ecological resilience, but there is a detrimental vacuum of ethnographic understanding. Research relevant to climate change is restricted to etic, survey analysis. This research is invaluable but cannot resolve deeper "why" questions regarding political, social, and economic movements in the West. Furthermore, the survey data from within Canada is severely limited, making any analysis of non-indigenous Canadian society vague and riddled with caveats. This paper discusses the academic neglect regarding the cultural resiliency of non-indigenous, Western societies. From existing literature, the author constructs a research framework for Alberta, Canada - the province placed at the crux of the national climate change debate. Anthropological institutions must ask themselves why this demographic is excluded from the same critical analysis applied to indigenous and nonWestern societies and move to correct this discrepancy.

\section{Introduction}

Climate change remains a persistent societal problem in local and global discussions. For anthropology, an important part of this discussion is the resilience of a cultural community. Simply put, there is a concern that climate change can impact whether cultural norms and hierarchies stay the same or change. Crate and Nuttall (2016) showed how the expansive body of knowledge that anthropology produced on cultural resilience is focused on marginal or Indigenous communities, and consistently in the context of industrial impact. The orientation of research questions in anthropology, regarding cultural

Megan Paranich is a Master's student at the University of Alberta (Department of Anthropology (13-15 HM Tory Building, Edmonton, Alberta, T6G 2H4 [paranich@ualberta.ca]). resilience, is fixed on what could be called nonWestern or Indigenous communities. Later sections in this paper will also show how, on a broader scale, social studies of communities show a methodological bias as well, between studies of so-called Western and non-Western societies.

The purpose of this paper is to examine the social research that has been conducted on socalled Western society with regard to climate change in order to clarify what exactly is missing from the body of literature. For this purpose, some terminology must be contextualized and defined.

\section{Cultural Resilience}

Anthropology borrows the term 'adaptation' from biology to describe social changes that happen in regard to changes in "natural resources for social 
reproduction and long-term survival" (Crate and Nuttall 2016:58). Anthropology also borrows the concepts of 'vulnerability' from disaster research, and 'resilience' from ecology-both of which relate to the degree of success generated by sociocultural strategies (Crate and Nuttall 2016:58). These three concepts intersect within the workings of a culture to create various responses to climate change information.

This paper is specifically focused on resilience, because this is a property of a community that emerges from a kaleidoscope of factors that includes how people assess their own vulnerability and risk, and how they decide to change or persist. It is 'cultural' because it involves moral hierarchies that would then guide economic or ecological strategies.

\section{Western}

The term 'Western' is a problematic one to use. Its boundaries change with political or rhetorical interest. It is a term that can refer to the western hemisphere, but in the literature, it rarely conceptually includes Central to South America. This definition also excludes Europe and Australia, both of which are often labelled as Western in both academic and colloquial language. Within countries that are called Western and are also post-colonial states, this term is not applied to Indigenous communities. Therefore, the capitalized 'Western' is not a geographical term - it is a demographic term. The people referred to as Western in the following literature review are overwhelmingly Caucasian (white), and of European descent. That being said, the racial aspect of demographic is not always explicitly discussed, but in the literature reviewed in this paper, there is a latent assumption across the board that if the population is not white, then they will be directly defined.
If the population is white, then they are simply termed 'Western.' This is an important distinction to consider, when reading through the material.

\section{Indigenous}

The term 'Indigenous' is also a contentious one, as it creates the sense that all communities that are indigenous to colonized areas are the same, by virtue of that indigeneity. This homogenizes the cultural beliefs and political positions of each group, collectively lumping them as a whole category. The reason why this paper will continue to use 'Indigenous' as a category is not to validate the idea that whole nations are indistinct, but rather to discuss the reference point of the conflicts discussed in the literature reviewed.

The literature reviewed has a collective reference point of Western as distinct from Indigenous. Where studies review a specific Indigenous nation, then the nation is treated as distinct. However, when a study reviews a socalled Western nation-state, there is rarely explicit consideration of Indigenous communities within those nation-states. They, as a whole category, are not considered as a part of the dominating discussions of the countries called Western.

There is also a methodological split defined by the conceptual groups of Western and Indigenous. As discussed in later sections, those deemed Western are treated to the positivistic approach, while those considered Indigenous are studied more through ethnographic approaches.

When the terminology temporarily changes from Indigenous to First Nations, the term is explicitly and preferably used by the literature discussed. The change is relevant to the discussion in this paper, specifically regarding how research writing has adjusted to meet new standards of practice. 


\section{Scientific Hegemony}

Epistemology - the nature of knowledge, or the rationality of belief-is a major theme in this review. Throughout the literature review, it is important to keep in mind the dominance of science as an epistemology. This is not just as a way of knowing the world, but also as a way of talking about the world. The very discourse of science shapes much of the discussion in the literature that is reviewed. Furthermore, there is significance to how different types of knowledge are treated in the literature, even indirectly.

The normalized dominance - or hegemonyof science and scientific speech holds much power over how they interpret their environment (e.g. Lelas 2000; Shapin 1998; Shapin and Barnes 1977). Stoddart (2007) relates this hegemony of scientific discourse to the individual and collective understanding of humanity's context in relation to resource production and socioeconomic structures - all of which relate to cultural resilience. When considered in discussions of climate change, this way of knowing and speaking about the world invariably affects how people perceive the human and nonhuman processes that are involved.

\section{Emic and Etic}

For the purpose of this paper, I will use the terms 'etic' and 'emic' in the way they are used by Crane (2010). Crane (2010) refers to the surveybased, positivistic methodology as 'etic' in the sense that it frames meaning as external to the people being considered in the study. Crane (2010:18-19) states, "[i]n brief, in an etic analysis of a system, behavior or belief seeks to frame the study in terms that are explicitly external to the subject being analyzed. In etic approaches, the terms of analysis may not have any particular meaning to the subject of study." Crane (2010:19) makes connections between this etic definition and disciplines like human ecology, which ask questions about "behavioral or materialist research." In regard to how 'emic' relates to 'etic,' Crane (2010:19) states,

...emic analysis is more associated with cognitive or social-constructivist research approaches, such as belief systems and identity... this work starts from the premise that the more interesting challenge is to explore the relationships between collective cultural experiences and meanings (emic) and external analysis of behavioral practice (etic) in the context of adaptation to environmental variability and change.

It is with these definitions that I will carry through this critical literature review. This is indeed a generalized way of dealing with the conceptual separation of these research approaches, but I believe it is very useful.

\section{The Review}

It may seem obvious to point out that climate change imposes social effects in terms of how the local weather and climatic patterns are interpreted by collective and personal perceptual frameworks (Bostrom et al. 1994; Weber and Stern 2011; Akerlof et al. 2013). Climate change science does not explain the patterns of human social engagement with their environment, as this is "neither a biological nor a technical response of an undifferentiated population to physical or material conditions" (Crate and Nuttall 2016:59). This is why sociocultural studies must be done in order to answer the questions that fall outside of the range of scientific investigation. The studies that are reviewed in this paper primarily focus on how climate change affects Western society. The critique that follows will focus on who is studied, and how research questions are investigated. 
The Impact of Climate Change on Western Society: What Do We Know?

\section{Politics and Science Communication}

According to Allan (2017:131), "from 1600 to 1950 , the word climate referred to local weather patterns but today it refers to a global geophysical system subject to multiple forms of governance." Before 1950, discourse about climate change and environment treats the climate as this single scientific definition. However, within the presentday scientific community there are numerous definitions of climate, depending on the field of study (Allan 2017:131-32). The geophysical model translates climate change as a predictable phenomenon, which can be modified by the addition or subtraction of carbon dioxide $\left(\mathrm{CO}_{2}\right)$ in the atmosphere. However, non-geophysical scientific models translate the phenomenon as non-linear and volatile, built into a complicated biosphere that also incorporates numerous other processes and variables (Allan 2017:132). Allan (2017:131) explains that various elements of the biosphere can be reduced to one focus of climate change policy discussion, which is then "targeted by the rationalities and technologies of global climate governance." In other words, climate and environmental models across scientific disciplines are complex, each putting emphasis on different aspects of the environment. Different groups of people will choose different models, each emphasizing what might appear to be conflicting perspectives outside of the scientific community (Sarewitz 2004:388-393). Even within the scientific community, there are many ways that the results of a study can be translated into both the public consciousness and policy (Allan 2017; Cooter and Pumfrey 1994). The history of science as emerging from state politics, as well as from the sociocultural position of individual scientists, influences much of the contemporary discourse regarding climate change (Allan 2017:139).

The denial of climate change as a real, anthropogenic phenomenon did not begin in scientific communities. According to Dunlap and McCright (2011:155), the public movement of climate change denial began in the United States and spread to other nations "often with some degree of assistance from American actors." The nations with the strongest degree of climate change denial "have or have recently had conservative governments" (Dunlap and McCright 2011:155), with strongly established conservative think tanks that actively oppose national and global environmental policy. In their text, Dunlap and McCright (2011) draw a strong causal link between free-market political conservatism, support for the fossil fuel industry and climate change denial campaigns. These concerted efforts of denial undermine the notion of a scientific consensus, which influences the policies a voter may support. McCright and Dunlap (2011a:1169-71) describe the distribution of belief between Republican-identifying and Democrat-identifying voters in America. Democrats are more likely to agree with scientific consensus regarding climate change and the appropriate environmental policy, while Republicans were more likely to deny climate science. Republicans were also less likely to actively seek information with respect to environmental issues (McCright and Dunlap 2011a:174-5). McCright and Dunlap (2011b) discuss climate change denial as highest in America among white conservative men. In these studies, political identity appears to be the key component of perception.

Using survey data from the Association of Professional Engineers and Geoscientists of Alberta (APEGA), Lefsrud and Meyer (2012) 
examined the attitudes of professional geoscientists and engineers in Alberta towards climate change. The source is important, because APEGA polled its active members, meaning that each member met minimum requirements of education and work experience in professionally relevant fields (Lefsrud and Meyer 2012:1484). The data has a baseline consistency that gives the conclusions much more authority due to the consistency of their data pool. The authors found that scientific literacy was not the essential factor in whether or not an individual accepted climate change as real and man-made (Lefsrud and Meyer 2012:1498-1500). Respondents in private industry were less likely to accept climate change as anthropogenic, while those in the public sector were more likely to do so. Those opposed to climate-change-oriented environmental policy were more likely to be older, male, and/or working in private industry. Respondents who were younger, female, and/or working in the public sector were more likely to support such policies (Lefsrud and Meyer 2012:1492-1494). Lefsrud and Meyer (2012) demonstrate that there are other demographic factors involved in belief that go beyond scientific literacy - as in, it does not matter if someone understands science or not, because there are other aspects of peoples' lives that can influence belief.

However, understanding science still matters. Sociocultural position alone cannot explain some of the beliefs that are in conflict with the scientific consensus on climate change. Indeed, the idea of consensus among scientists is itself a problematic topic. Despite studies supporting consensus in the academic science community (Cook et al. 2013; Cook et al. 2016; Doran and Zimmerman 2009; Maibach, Myers, and Leiserowitz 2014), van der Sluijs, van Est, and Riphagen (2010) reveal how the Intergovernmental Panel on Climate Change miscommunicated the existence of a scientific consensus through poor methodology. Van der Sluijs van Est, and Riphagen (2010) discuss how scientific uncertainty interacts with public policy, and this study should be referred to in future studies that focus more closely on the construction of environmental policy. There is a widespread demand on the scientific community to take a unified and confident stand on issues related to the environment. However, both the public and the scientific community regard consensus, confidence, and uncertainty in different ways (Oreskes 2004; Sarewitz 2004). This demand for unanimous consensus reveals a significant miscommunication between scientific and non-scientific communities as to how science-specific peer review processes work, as well as how the language of probability and uncertainty functions within scientific communities (Oreskes 2004; Sarewitz 2004). The peer review process of scientific publication creates a constantly adjusting dialogue of what is or is not valid. This fluidity of scientific discussion leaves room for further criticism and doubt from non-experts, in that it can be interpreted as inconsistent. Studies cited by van der Linden et al. (2015) reveal that perceived expert consensus is essential to the American public's acceptance of climate change. This means that the smallest dissent or doubt can heavily influence the public in withdrawing their support. The perception of scientific agreement is what van der Linden et al. (2015:2) identify as a "gateway belief." Their Gateway Belief Model (GBM) shows how a change in the degree of perceived scientific consensus directly causes a change in the beliefs in the existence, anthropogenic nature, and perceived risk of climate change (van der Linden et al. 2015:6). The authors found that when consensus-oriented messaging was prioritized, the shift in belief system was consistent across other demographics of perception, such as Republicans and 
Democrats in America (van der Linden et al. 2015:6-7).

\section{Do We Know What Climate Change Is?}

The scientific community agrees that climate change is an anthropogenic phenomenon that is currently happening (Cook et al. 2013, 2016; Doran and Zimmerman 2009; Maibach, Myers, and Leiserowitz 2014). Conservative political discourse injects doubt into the public perception of climate change, which expands beyond the binary of "real" or "not real." Where climate change is held as at least partially real or climate change science is at least partially valid, there are numerous beliefs regarding the origin of this phenomenon.

Bostrom et al. (1994) studied American perceptions of scientific ideas with respect to climate change and greenhouse gases, and the authors illuminate disconnections between expert and non-expert understandings. Furthermore, the authors found fundamental misconceptions among the American public about how global warming impacts atmospheric processes. For example, although the main chemical of concern with climate change is $\mathrm{CO}_{2}$, many respondents believed that the chemical was cholorfluorocarbons (CFCs) (Bostrom et al. 1994:961-62). The respondents had confused climate change with ozone depletion - both atmospheric phenomena but resulting from two significantly different sources. The respondents who believed CFCs were responsible for climate change would then associate CFC use, and not fossil fuel use, with climate change-related pollution. This misconception would then affect the actions that they would be willing to take. These misconceptions were not a function of whether or not the respondent believed in climate change, but rather what the individual understood climate change to be in the first place. The misconceptions were embedded in accurate reflections of unrelated scientific fact, which alternatively made the scientifically inaccurate beliefs far less cognitively isolated and difficult to separate (Bostrom et al. 1994:968-69). This blend of awareness and misconception in the American public's mental framework makes instilling effective environmental remediation significantly more difficult. The researchers found that even when members of the American public believed in climate change and were positively responsive to environmentalism, they were less capable of distinguishing what strategies would or would not work in response to climate change due to this collection of unrelated beliefs.

To explain this disconnection, Weber and Stern (2011) summarize research that describes the perceptual frameworks of the American public dating back to the 1990s. There are significant differences in how concepts of environment, pollution, climate change, greenhouse gases, and their impacts are understood between experts and non-experts. Weber and Stern (2011:318-19) claim that the public base their understanding on affective and associative reasoning, and that climate scientists function under a peer-reviewed, analytical process that largely removes the personal experience from their published conclusions. The peer-review process of scientific institutions creates a separation of standards between how the non-expert public determines fact and how the scientific community does the same. This is not necessarily an indictment of the subjectivity of scientists, which has been studied since at least the 1950s (de Gre 1955 [2012]; Latour and Woolgar 1979). Rather, this separation of standards in itself indicates an overly simplistic view of how non-scientists receive and process scientific knowledge, and that this view has made its way into the reasoning of social studies. 
Cooter and Pumfrey (1994) explain how science diffuses to the public spheres and is transformed into so-called "popular knowledge." They find that there is an imperfect diffusion that can instigate misunderstandings of the information being transmitted, and of the processes that create that information. In August 2017, the Ontario Science Centre (OSC) polled Canadians, and found that $47 \%$ of respondents did not believe scientists had enough information about climate change (Ontario Science Centre 2018). This is a seven percent point increase from the same survey conducted the year prior. Although their findings report that $82 \%$ of respondents trust science centres and museums as sources of scientific information, $43 \%$ of respondents believe that science is a function of opinion. Survey and statistical data are inherently flawed due to respondent bias, yet these trends show a change in how respondents perceive the trustworthiness of science.

The perceived location of climate change also matters. Risk perception relies on an individual's perceived proximity to the effect of climate change. Leiserowitz et al. (2013:1-11) polled Americans and found an inverse correlation of perception of threat with perception of distance. Those far away from the respondents, both geographically and emotionally, are seen as being at greater risk, while those within the respondents' immediate experience are deemed to be at less risk. Leiserowitz et al. (2013:11) see that a similar pattern emerges with how their participants perceived the dichotomy of so-called 'developed' versus 'developing' countries, where those in highly industrialized countries were at less risk from the effects of climate change. Lorenzoni, Nicholson-Cole, and Whitmarsh (2007:447-52) cite previous studies regarding the internal and external influences on environmentally oriented action. The authors found that there is a strict locality to the perception of danger and the need to act. People were not motivated to action if they considered it a problem foreign to their immediate geography. This is consistent with the findings of studies across Europe and America. There is no study that was available to this review that replicated these findings or questions with the Canadian public.

Akerlof et al. (2013) discuss the conflicts between the immediacy of the experience of temperature for the layperson with the long-term analysis of climate by the scientist. Again, we see a split forming between the groups of "scientists" and "public." However, for Akerlof et al. (2013), this is not a problem, as their research focuses on the access to resources and information that creates difference between the groups, not an assumption about any fundamental discrepancy in social values or perceptual frameworks. Climate is usually described over thirty-year periods, and whereas scientists have access to data-sets, modeling software, and the educational background to tackle such analysis, the public generally does not (Akerlof et al. 2013:82-83). The geographic and temporal scale of an experience also added dimensions as to what a respondent would believe. The survey used by Akerlof et al. (2013) directly asked respondents whether they had personally experienced global warming. The authors sorted open-ended respondents by what types of indicators the respondents had experienced, if any at all. The top four indicators were changes in seasons, extreme storm events, changing water levels in lakes, and increased snowfall (Akerlof et al. 2013:85). Of these four categories, only the first three experiences were consistent with regional weather and climate data, with snowfall showing a decreasing trend (Akerlof et al. 2013:86-87). The authors found that individual perceptions of weather and climate on the local level are embedded with "culturally constructed meaning" 
(Akerlof et al. 2013:89), which influences how they perceive information communicated about those weather or climatic events. Akerlof et al. (2013:90) cite a "collective irrationality" to the perception of global warming, but also indicate that there is a small portion of the population studied that can extract themselves from their personal frameworks to acknowledge the directly measured changes around them.

Geography also matters in understanding the differences in environmental action within a nation-state. Semenza et al. (2008) examine two American cities to determine social barriers to taking environmentally conscious action. They chose Houston, Texas and Portland, Oregon. The cities are ecologically different, and they have distinct urban planning policies and political orientations (Semenza et al. 2008:485). Recall the correlations drawn by van der Linden et al. (2015) and Weber and Stern (2011) regarding political ideology, and one would expect glaring differences in the belief profile of each city. However, researchers found that gender and economic brackets were more significant than the overall political affiliations of each city (Semenza et al. 2008:481). Semenza et al. (2008) found that in these two American cities, women and lowincome individuals were significantly more concerned about climate change. The difference in the two cities did not emerge in what people believed, but what actions they took while holding those beliefs. A higher percentage of Portland residents $(63 \%)$ reported changing their behavior in a response to understanding and accepting climate change than Houston residents (47\%) (Semenza et al. 2008:482). Regardless of whether a person believes in climate change, there are other factors in the lives of individuals that must be considered as reasons for actions that seem contrary to environmental concern. In this sense, the researchers acknowledge that there are finer experiential factors to be considered.

\section{The Role of Economics}

Crate and Nuttall (2016) note that an important aspect of a survival framework for a given society is economic certainty. Cultural stability and economic stability are invariably linked (Lockwood 1974, 1992). The livelihoods of people are largely dependent on providing for themselves and their familial or communal units. The perception of economic risk may influence the perception of other sources of danger. Scruggs and Benegal (2012:507) found that acceptance of climate change as real in the United States fell significantly after the 2008 American financial crisis. From over forty years of public opinion data regarding climate change, the authors concluded that in both American and European societies there was a significant correlation between climate change denial and financial insecurity (Scruggs and Benegal 2012:505). Capstick et al. (2015:40) show that public concern regarding climate change rose through the mid-1990s to the mid-2000s, yet this trend was followed by a period of doubt and marked polarization "within and between nations." The decline correlates with the timing of the 2008 financial crisis. Therefore, belief in climate change becomes a matter of priority. In times of economic crisis, when an individual's concern is focused more on their personal income and day to day survival, the long term and vaguely experienced effects of climate change cease to be a priority (Capstick et al. 2015:50). Survival then becomes a matter of a paycheck, rather than the movement of a coastline.

Lorenzoni and Pidgeon (2006) examine how public perception of the risk of climate change varied in the United States and the European 
Union (EU) with respect to concurrent events in local and global news. They found that in pre9/11 surveys, the environment was the most important global issue to those populations, but in 2002 concern began to decline and climate change was eventually replaced by terrorism and domestic concerns by 2004 (Lorenzoni and Pidgeon 2006:76). Climate change is considered a long-term risk, while financial and security concerns are far more immediately felt, which tends to overwrite long-term risk assessment (Lorenzoni and Pidgeon 2006:74; Scruggs and Benegal 2012:513-14). This tendency results in the prioritization of action as explored by Whitmarsh (2009), who connects existing environmentally conscious behavior in the United Kingdom (UK) with financial motivations rather than environmental concern. For example, Whitmarsh (2009:19) connects actions like switching to energy-efficient technology to financial causes, like saving money, instead of environmental consciousness. Concern for the environment may be present, but this does not mean that it is a determining nor significantly influential motivator of individuals' actions. The author defines this as an asymmetry between intention and impact (Whitmarsh 2009:19). This asymmetry is necessary to understand in behavioral analysis so that researchers do not attribute an action to a motivation that the individual in question does not have.

In Canadian society, the most comprehensive risk assessment with respect to climate change was carried out in a public health framework. Berry et al. (2009) itemize the health impacts of climate change and how the public conceptualized these risks. This study reveals that Canadians do not immediately think of climate change as a factor in their health or physical wellbeing, unless prompted to consider it. The study also reveals a skew in climate change acceptance towards younger generations and a pronounced skepticism of risk in the Prairie Provinces. These heterogeneities may be due to shifting social values along generations and geography. Alberta is among the Prairie Provinces that expresses pronounced doubt in climate change risk (Berry et al. 2009).

According to 2016 economic reports on the Government of Alberta's website (Government of Alberta 2016), Alberta's economic structure is heavily dependent on the development of fossil fuels. The development and use of fossil fuels generates $\mathrm{CO}_{2}$ - the leading cause of anthropogenic climate change, discussed in previous sections. This puts the industry in direct opposition to climate change activism and policy. According to economic reports by Statistics Canada, in 1985, oil, gas, and mining in Alberta contributed to $36.1 \%$ of the province's gross domestic product (GDP) - the largest economic contribution by over twenty percentage points (Statistics Canada 2016). By 2015, the contribution was down to $18.3 \%$, with significant percentile growth in other pre-existing fields. At first glance, this may lead one to believe that Alberta's economy is diversifying away from oil and gas developments. However, the fields of expansion involve finance, real estate, construction, and business and commercial services, which are deeply embedded in the oil and gas industry. These real economic impacts of Alberta's fossil fuel developments must be held against the local and national narratives generated about its importance.

Climate change mitigation efforts are diametrically opposed to Alberta's core industry, in that the oil sands rely upon and fuel the propagation of $\mathrm{CO}_{2}$ emissions. This emerges in the performance of the Alberta government, especially in how it structures its internal policies. Way (2013) provides an analysis of how discourse shapes these policies, and Hackett (2015) elaborates how the market-based 
governance in Alberta fails to succeed in the maintenance of the status quo. The inability to move beyond set policy patterns is a significant signal to the entrenchment of free-market economic values in Alberta. This exists, despite the detriment to its people, state, and land (Hackett 2015). Harrison and Sundstrom (2007) indicate that voter apathy among American and Canadian voters is a significant reason for that lack of progress of climate change policy.

In the countries studied by Harrison and Sundstrom (2007), which included Canada and the United States, environmentalists were supportive of international and domestic environmental policies, such as the Kyoto Protocol. The authors found that business and labor opposition is correlated to the degree of carbon emission reductions below the businessas-usual baseline outlined in the Kyoto Protocol (Harrison and Sundstrom 2007:6-7). The authors also observed that although there is scientific consensus, there is substantial political debate about the existence of climate change (Harrison and Sundstrom 2007:7-8). They consider this political disagreement to be a defense of business interests rather than a genuine inquiry into the validity of climate science.

Regarding Canada, Harrison and Sundstrom (2007) identify the decentralization of federalism as a significant obstacle to the implementation of environmental action on a national scale. This is due to the provincial jurisdiction over natural resources, like fossil fuels. The two provinces most dependent on the propagation of fossil fuel use are Alberta, with oil and gas developments, and Ontario, with automobile manufacturing; in fact, these provinces provide the strongest opposition to environmental policies that aim to reduce reliance on fossil fuels (Harrison and Sundstrom 2007:10-11).
From the information summarized in these sections, we can state what is happening regarding belief in climate change with confidence. Political ideologies have an influence on what information an individual will accept as true or false. We know that age, gender, and sector of career are significant to what an individual believes as well. We can also say that economic structures influence how people prioritize risk, and that discourse has an influence on how some communities conceptualize the environment, pollution, and climate change.

Science as the hegemonic epistemology has shaped Western images of nature and non-human things. It has become a hegemonic way of knowing the world, and as such holds much power in terms of what people believe about their environment (e.g. Lelas 2000; Shapin 1998; Shapin and Barnes 1977). Specifically, Stoddart (2007:199) holds scientific discourse as responsible for the ideas of nature as "something predictable and controllable." It is the heavily object-oriented perspective of science that allows it to produce the knowledge it does, but it also creates a worldview that disconnects people from the non-human world (Lelas 2000).

In the field of climate change, academics have regarded Indigenous and marginalized societies from Crane's (2010) emic perspective, yet industrialized nations are almost exclusively regarded through Crane's (2010) etic, positivistic research approach. The examination of Western resiliency has thus far been largely in the context of economics, medical health, and resource ecology. The 'etic' approaches applied to Western communities also do not consider the Indigenous communities that also live in nationstates like Canada or America.

I believe that part of the reason for this is that the dominating view of science is somehow 
unique in its relationship to society. This emerges in humanities research when scientists are treated as being uniformly value-free and separate from the public, as in the research of Weber and Stern (2011), despite the long-standing literature of the sociology and anthropology of science. The authors demarcate scientists as being isolated from the public, and therefore not influenced by the same biases and dependency on perceptual frameworks. They fall into the perceptual trap that much of the Western world is obsessed with-science is a disembodied and dislocated "view from nowhere," when in fact it is no such thing (Shapin 1995:5). In allowing themselves to regard scientific practices or scientists as valuefree and separate from sociocultural influence, researchers eliminate any consideration of shared history, social morals, or political bias. Weber and Stern's (2011) treatment of scientists as value-free, however fleeting, is a notable error; there is a plethora of research that precedes these authors that addresses this very concept. They leave unaddressed the hierarchy of power that situates science as an absolute authority, while diminishing other systems of knowledge, such as local or tacit. Furthermore - as many other papers in this literature review do-by operating within a conceptual model of 'public versus science' or 'Western versus Indigenous,' humanities researchers not only erase the heterogeneity of knowledge within these imagined groups, but also the congruencies between them. Of course, these false dichotomies also ignore a large body of research that precedes them.

The work of Lorenzoni, Nicholson-Cole and Whitmarsh (2007) makes a particularly important point in that the 'Western' people they surveyed did not believe that climate change would impact 'Western' countries. This perception, discussed in the previous section, flags an assumption held in those communities about their own ecological, economic, and cultural resiliency that has not been examined by 'emic' methods. I also postulate that this latent assumption may be why Western anthropologists have not examined their own society in this context, in ways similar to how they examine "other" places and people. There appears to be an implicit assumption among respondents and researchers that the emic world of the West does not have to be considered in the same way that the emic world of the nonWest must be.

Furthermore, Akerlof et al. (2013) describe the actions of their study respondents to be irrational. I believe this is not only misrepresentative but can lead to further misconceptions about these communities by researchers. It also does not provide an acceptable answer to behavioral questions. I believe that the authors describe the beliefs and actions of the respondents as irrational, because they are missing key information about underlying cultural logic. I ultimately find the conclusions reached by the researchers discussed to be disappointing. Unfortunately, the large body of research on both science anthropology and 'Western' knowledge systems is not integrated into the literature about how climate change affects non-indigenous, 'Western' people. Although, the literature reviewed does provide excellent information to create the basis for such a study.

The results of these studies are consistent with survival frameworks and the selfpreservation of cultural moralities-topics in which anthropology is well practiced. For example, Crate and Nuttall (2016:61) discuss survival frameworks of society in terms of "food production, shelter, and, at the most fundamental level, security." However, these survey-based findings lack a practical significance, in that they neglect any discussion of cultural influences beyond a superficial acknowledgement of shared values. The contributions of more 'emic' 
methodologies can take these further by reconfiguring these datasets into a humanistic context that is more capable of filling in the remaining gaps in understanding.

The studies of Lorenzoni, Nicholson-Cole and Whitmarsh (2007) and Harrison and Sundstrom (2007) both recommend potential avenues of change to help Western societies adapt to climate change and the challenges it brings. Whereas Harrison and Sundstrom (2007) indicate a voter-initiated, bottom-up approach would be most effective, Lorenzoni, Nicholson-Cole and Whitmarsh (2007) recommend a top-down approach. The top-down approach would make use of existing social hierarchies of power and would be well aligned with the pro-environmental cultural dynamism occurring in younger generations. This would be an adaptive strategy; wherein economic powers can retain at least a superficial retention of influence. Relying on a bottom-up approach, I believe, requires the interruption and break-down of social and moral hierarchies related to extant socioeconomic and sociopolitical structures. Additionally, the singular causal link between politician and voter apathy is far too simplistic, and studies by both Lorenzoni, Nicholson-Cole and Whitmarsh (2007) and Harrison and Sundstrom (2007) fail to take into account the various sociocultural hegemonies that influence collective and personal decisions. Ultimately, the degree of resistance to this type of change is about risk assessment, and the negotiation of realities within frameworks of not just practical, physical survival, but the survival of social orders and moralities. Economic stability is a vital part of this (Lockwood 1974, 1992), and whether someone is a climate change believer or denier becomes far more significant when we consider the implications of climate change to the existing economic, social, and political orders. The work of Stoddart (2007) in this framework is of particular significance.

Climate change denial reflects a hegemony of economic ideology and the prioritization of the maintenance of the political status quo. Way (2013) is an excellent example of a comprehensive study that examines how Canadian news outlets discuss the nation's oil industry. Way (2013) thoroughly examines how provincial and national news media portray the economic importance of the fossil fuel industry, specifically the Albertan oil sands. The author finds that Canadian news media generally and consistently follow a neoliberal slant that strongly supports fossil fuel development - an action in direct conflict with climate change environmental policy. The author finds that daily newspapers categorize the oil sands under business sections, which institutionalizes the oil sands within financial discourse, rather than environmental. Moreover, Canadian news media were more likely to blame governments than industrial activity for economic and environmental policy failures. Critiques of the oil industry were treated as controversial stories, with counter-arguments from favorable politicians and industry leaders published as responses. Way (2013:59) defines two dominant discourses in Canadian news media: augmentative and transformative. Augmentative discourses are defined as, "those that affirm the values associated with a neoliberal policy frame (e.g., private sector's role as lead developer) as well existing neoliberal oil sands policies (e.g., the royalty regime). Actors that benefit from the existing policy frame-and/or subscribe to its values - are most likely to advance this type of argument." Transformative discourses run contrary to augmentative discourses in that they are defined as those "which challenge the 'facts' and values used in support of neoliberalism" (Way 2013:88). Way 
(2013) indicates that the Alberta government under Ralph Klein shifted oil sands discourse away from other resource areas such as conservation, moving it towards a neoliberal framework.

Way (2013) asserts that the Government of Alberta was building policies within an augmentative discourse, and that transformative policies ultimately failed to become a success in Alberta. Neoliberal discourse was also reinforced after the federal Conservatives were elected to power in Ottawa (Way 2013). From 2006 to 2008, the Albertan public began to shift away from neoliberal approaches to environmental issues, which coincided with increased receptivity for First Nations concerns (Way 2013). Although the discourse remained dominantly augmentative, and the lean of news reporting remained consistently neoliberal, governing bodies and the Alberta public responded by questioning the nature of policy frameworks. The neoliberal framework of values in the province has been resilient to doubt from the public, something Way (2013) attributes to the tone of news reporting nation-wide. The author further notes that neoliberal ideologies have become less controversial and equated with "common sense" (Way 2013).

Way (2013) breaks down how oil sands news was specifically reported within Alberta, other provinces, and in national news articles. Interestingly, Albertan newspapers gave more attention to environmental and social impacts than national media, and specifically the Toronto Star (Way 2013:187). Non-Albertan papers tended to prioritize these environmental articles in the context of energy security (Way 2013:187). Way (2013:190-99) found that newspaper reporting of the oil sand industry consistently focused on the economic contexts of the reported issues. The author found that an "augmentative discourse upholding a faith in the free market" was heavily dominant throughout news outlets, including those oriented towards energy security (Way 2013:199). Transformative discourses were present in environmental articles, but filtered through an augmentative reporting system, thus muting and marginalizing the transformative perspectives (Way 2013:199). The differences in the distribution of topic contexts between national and provincial scopes indicate the variability in public concern and opinion (Way 2013:199-200). Way's (2013) dissertation also shows an overall trend towards the maintenance of the status quo, which reflects societal tendencies to resist disruptions that are harmful to the foundation of its normative moralities (Crane 2010; Lockwood 1992; Stoddart 2007). The maintenance of this status quo is not solely couched in news media. The political performances of fossil fuel dependent states are very telling in how they seek to defend their socioeconomic interests.

Environmental action and policy oriented towards the belief that climate change is real and anthropogenic potentially reflects counterhegemony in Alberta. At the same time, the adherence to climate change belief reinforces the hegemony of scientific discourses, while, on an international scale, the resistance to climate change belief, based on claims of no or little scientific consensus, represents its own counterhegemony. Climate change is not simply a matter of volatile storms and rising sea level-it has created tensions both within and between hierarchies of power, knowledge, and politics within the Western world. These tensions illuminate internal structures that put social moralities and constructions in between a rock and a hard place, where they must internally adapt, or fall towards the uncertainty of cultural transformation.

These shifts in the power hierarchies of discourse and knowledge are discussed by Crane (2010) in terms of resilience and cultural 
adaptation. In these terms, the personal subjective perception feeds off and contributes to the collective nature of normativity. Crane (2010:18) distinguishes normative and subjective perceptions as collective and personal, respectively. There are tensions between resilience as an ecological concept and resilience as a cultural process capable of shaping normative cultural moralities. The individual experiences and perceptual frameworks - the parts that make up the whole - play an important role in cultural resilience, which Crane (2010:20) defines as "the ability to maintain livelihoods that satisfy both material and moral (normative) needs in the face of major stresses and shocks; environmental, political, economic, or otherwise." To Crane (2010:20), changes in "behaviors, values, and social institutions" are a part of cultural dynamism. However, cultural transformation occurs when a shock to the system creates a disruption sufficient to disconnect social institutions, normative values, and daily life (Crane 2010:20-1). Crane (2010:21) contextualizes climate change under Durkheim's concepts of anomic declassification. Crane (2010) uses this concept in a way that means that largescale environmental disruptions, which affect the economics and routines of daily life, could culminate to a threshold at which social stratifications of morality and normativity begin to break down. This would result in the reorganization of society, and such a powerful deconstruction would redistribute economic power "on a scale too large to permit of their constant containment with the existing moral hierarchy" (Lockwood 1974:366). In this way, the existence of climate change can threaten social orders that rely on consistent environmental or economic patterns. However, Lockwood (1992:334) notes that crises such as these alone were "insufficient conditions of revolutionary action." It is important that we then understand the internal cultural movements in order to understand the orientation of actions that may seem irrational or unpredicted. These actions could be revolutionary, or they could emerge as new cultural practices.

Crane, Rancoli, and Hoogenboom (2011:184) find that the adoption of new practices-like pro-environmentalist policy or behavior - is related to the perception of cultural adaptation, and that the acceptance of this adaptation is "heavily influenced by social history and constructs of ethnic identity, which are closely linked to livelihood niches." The positivistic approaches used by the social studies of Western societies and climate change belief tend to overlook "these fundamentally normative positions as influential factors in adaptation" (Crane , Rancoli, and Hoogenboom 2011:184). The authors of many of the studies discussed above have contributed much towards understanding the belief landscape, but ultimately fall short due to the positivistic nature of their approach. However, Crane, Rancoli, and Hoogenboom (2011) approaches adaptation and behavioral responses in agriculture in Mali and the United States as social performances. In the context of social performance, the decisions made by respondents in the study conducted by Semenza et al. (2008) make much more sense. Furthermore, considering how political orientations now have communal identities, such as the ones described by McCright and Dunlap (2011ab), it would benefit the understanding of the communal actions of those groups to study them in the frameworks of sociocultural performance. Therefore, I theorise that climate change belief or denial may critically hinge on how that belief or denial fits into the sociocultural performative frameworks of Western groups. This performance could be subject to further 
internal and communal negotiation with survival frameworks, which involves socioeconomic profiles. However, there has yet to be adequate engagement from the anthropological community in this specific research orientation to lay a foundation for these studies.

Furthermore, studies of the discourse of climate change would benefit greatly from the application of non-positivistic methodologies and theories that provide the 'emic' meaning that Crane (2010) calls for. Wiggins (2016) summarizes and explains the methodological framework of discursive psychology (DP), which builds upon the works of Austin, Goffman, Garfinkel, Wittgenstein, and other foundational authors in the study of performance and discourse, as relevant to anthropological theory. DP is not a practice of psychology, but it is a method of analysis that regards discourse as constructed and constructive, situated in continuously emergent social contexts, and is action-oriented (Wiggins 2016:6-23). It is a framework of analysis that is well suited to the anthropological study of discourse and performance, especially in the muddled milieu of contexts and identities that statistical and survey analysis cannot describe nor explain. Sociologist Nico Stehr (2018) has recognized the need for sociology to engage in climate change research in the West. It is now time for anthropology to follow suit, while dismantling our own latent presuppositions along the way.

\section{Futures}

The controversy that hounds climate change discussions among 'Western' societies is superficially situated in scientific debate. Embedded in this discourse are dynamics of scientific hegemony that compete with political ideologies and socioeconomic structures. There are entrenched worldviews of the objectivity and controllability of non-human nature perpetuated by both scientific discourse and the market-based governance. Political ideology and personal perceptual frameworks intersect to create identities entwined with climate change acceptance or denial. Either option becomes a performance - an enacted participation in discourses regarding the perpetuation or adaptation of social morality and norms. Influences of personal belief meet with social power structures. Belief is less about education, and more about the movement along cultural trajectories towards futures of either resilience or transformation. The choice itself - to accept or deny information-links to frameworks of survival and social performance. In any society, the survival of one's livelihood is not just a social survival-it is material, linking to factors of resource production and socioeconomic structures. There is a mutual connection between the way in which an individual provides for oneself, and how they perceive environmental changes. The disruption of this connection reveals the invisible forces of social power, morals, and normativity to which climate change undoubtedly applies pressure. Belief in climate change is a negotiation between existing social morals, scientific authority, political identity, and the maintenance of personal livelihood.

But there is little anthropological evidence to support any of these inferences taken from the overwhelmingly survey-based research that dominates the study of Western societies. The literature regarding cultural resilience and survival in the face of climate change is virtually exclusively about Indigenous, 'non-Western' people. False dichotomies dominate both sections of research, restricting conceptual groups of 'Western,' 'Indigneous,' 'scientific,' 'traditional knowledge,' and 'public knowledge' to fixed monoliths that are dangerously non-representative of their realities. The most damning part of this is 
that research explaining this has existed in the annals of academia, accessible to researchers but not effectively applied.

I have demonstrated the focus and limitations of the existing literature that addresses climate change in 'Western' society, and I have laid out how anthropology can move forward in this area of study. This is not to comment on any moral or academic wrong-doing in studying outside one's own society, but there is a visible neglect that has occurred with respect to turning our-as in Western anthropologists'-gazes inward. The lack of research questions that ask about the cultural resiliency of Western societies signals that there is no curiosity there. The lack of academic curiosity as to the cultural resiliency of Western societies could mean that this topic either has no potential for funding or that it is not regarded as a necessary focus of inquiry. Both options point to a latent bias in how Western anthropologists published in Western journals regard both their own society and other societies in terms of which cultural groups will or will not be morally affected by climate change. This discrepancy must be acknowledged, addressed, and fixed.

There is also a discrepancy in methodology. The language of the Western respondents to surveys have yet to be treated to the discursive analysis that is given to Indigenous and 'nonWestern' societies, in the specific context of cultural resilience. Way's (2013) dissertation is in the field of political science, and yet they have contributed more to the understanding of fossil fuel discourse in Alberta and Canada than have Canadian linguistic anthropologists. In fact, there is very little study in Canada at all, with the only other significant, Canadian-focused survey about climate change falling under the disciplinary orientation of public health or a brief survey on beliefs of geoscientists and engineers in Alberta
(Berry et al. 2009; Lefsrud and Meyer 2012). Furthermore, the scientists studied in the most prominent and widely respected works of science anthropology and sociology have been American. From my brief time as a geologist in Canada, I believe that there must be a more dedicated focus to how Canadian science is developing in the face of climate change and other environmental issues. This would invariably be supportive of any body of literature that would seek to understand the cultural resiliency of the Canadian public - both Indigenous and non-Indigenous.

My goal is not to divert academic attention away from Indigenous communities. But we must not ignore the fact that these communities remain under varying degrees of administrative control by decidedly non-Indigenous, Western institutions - the federal and provincial governments. We are also currently living in a time when one's relation to and belief in climate change is tied to political orientation. There is a vacuum of knowledge when it comes to not only Western-related knowledge, but specifically Canadian communities. To that note, it is not a disciplinary competitiveness that drives the thesis of this paper-it is the vacuum that sociolinguistic-cultural anthropologists can fill. It is time for anthropologists to do what they do best and bring human meaning back into global conflicts, like the struggle to understand and deal with climate change.

\section{Conclusion}

The existence and nature of climate change is no longer restricted to scientific inquiry. The implications surrounding climate change and cultural resiliency situate the phenomenon within the disciplinary scope of anthropology as well. Yet, due to a bias in research questions and methodology, Western societies are almost exclusively examined through surveys and 
statistics, unlike the non-Western societies examined with more qualitative approaches. This creates a separation as to where meaning is situated. For the non-Western, it is within their cultures, the resiliency of which is given the possibility of changing. For Western societies, meaning is situated as external to those within the society itself. Western cultural resiliency is not considered to be subject to questioning. Western anthropology, especially in Canada, must begin to turn its gaze inward, critically analyzing its own cultural resilience in the face of climate change. There is ample research that has laid a foundation for sociocultural and linguistic anthropology to begin to bridge this gap.

\section{References Cited}

Akerlof, Karen, Edward W. Maibach, Dennis Fitzgerald, Andrew Y. Cedeno, and Amanda Neuman. 2013. Do people "personally experience" global warming, and if so how, and does it matter? Global Environmental Change 23(1): 81-91.

Allan, Bentley B. 2017. Producing the Climate: States, Scientists, and the Constitution of Global Governance Objects. International Organization 71(1): 131-162.

Berry, Peter, K. Clarke, Mark Pajot, Dave Hutton, and Marielle Verret. 2009. The role of risk perception and health communication in adapting to the health impacts of climate change in Canada. Natural Resources Canada.

Bostrom, Ann, M. Granger Morgan, Baruch Fischhoff, and Daniel Read. 1994. What do people know about global climate change? 1. Mental models." Risk Analysis 14(6): 959-970.

Capstick, Stuart, Lorraine Whitmarsh, Wouter Poortinga, Nick Pidgeon, and Paul Upham. 2015. International trends in public perceptions of climate change over the past quarter century. Wiley Interdisciplinary Reviews: Climate Change 6(1): 35-61.

Cook, John, Dana Nuccitelli, Sarah A. Green, Mark Richardson, Bärbel Winkler, Rob Painting, Robert Way, Peter Jacobs, and Andrew Skuce. 2013. Quantifying the consensus on anthropogenic global warming in the scientific literature. Environmental Research Letters 8(2): 024024.
Cook, John, Naomi Oreskes, Peter T. Doran, William RL Anderegg, Bart Verheggen, Ed W. Maibach, J. Stuart Carlton et al. 2016. Consensus on consensus: a synthesis of consensus estimates on human-caused global warming. Environmental Research Letters 11(4): 048002.

Cooter, R., and Pumfrey, S. 1994. Seperate Spheres and Public Places: Reflections on the History of Science Popularization and Science in Popular Culture. History of Science, 32(97), 237-267. https://doi.org/10.1177/007327539403200301

Crane, Todd A. 2010. Of models and meanings: cultural resilience in social-ecological systems. Ecology and Society 15(4): 19-19.

Crane, Todd A., Carla Roncoli, and Gerrit Hoogenboom 2011. Adaptation to climate change and climate variability: The importance of understanding agriculture as performance." NJAS-Wageningen Journal of Life Sciences 57(3-4): 179-185.

Crate, Susan A., and Mark Nuttall, eds. 2016. Anthropology and climate change: from encounters to actions. Routledge.

de Gré, Gerard. 1995. Science as a Social Institution. Literary Licensing, LLC, 2012.

Doran, Peter T., and Maggie Kendall Zimmerman. 2009. Examining the scientific consensus on climate change. Eos, Transactions American Geophysical Union 90(3):22-23.

Dunlap, Riley E., and Aaron M. McCright. 2011. Organized climate change denial." The Oxford handbook of climate change and society (2011): 144160.

Government of Alberta. "Economic Results." Last modified May 24, 2016.

http://www.albertacanada.com/business/overview/econo mic-results.aspx

Hackett, Ryan. 2015. Market-based environmental governance and public resources in Alberta, Canada." Ecosystem Services 15: 174-180.

Harrison, Kathryn, and Lisa McIntosh Sundstrom. 2007. The comparative politics of climate change." Global Environmental Politics 7(4): 1-18.

Latour, Bruno, and Steve Woolgar 1979. Laboratory life: The construction of scientific facts. Princeton: Princeton University Press.

Lefsrud, Lianne M., and Renate E. Meyer. 2012. Science or science fiction? Professionals' discursive construction of climate change." Organization Studies 33(11): 14771506.

Leiserowitz, Anthony, Edward W. Maibach, Connie RoserRenouf, Geoff Feinberg, and Peter Howe. 2013. Climate Change in the American Mind: Americans' Global Warming Beliefs and Attitudes in April 2013. 
Lelas, Srđan. 2000. "Science and the End of Modernity." In Science and Modernity, pp. 271-279. Springer, Dordrecht.

Lockwood, David. 1974. "For TH Marshall." Sociology 8(3): 363-367.

- Solidarity and schism: The problem of disorder in Durkheimian and Marxist sociology. Clarendon Press.

Lorenzoni, Irene, and Nick F. Pidgeon. 2006. Public views on climate change: European and USA perspectives." Climatic change 77(1): 73-95.

Lorenzoni, Irene, Sophie Nicholson-Cole, and Lorraine Whitmarsh. 2007. Barriers perceived to engaging with climate change among the UK public and their policy implications." Global Environmental Change 17(3): 445-459.

Maibach, Edward, Teresa Myers, and Anthony Leiserowitz. 2014. Climate scientists need to set the record straight: There is a scientific consensus that human-caused climate change is happening." Earth's Future 2(5): 295-298.

McCright, Aaron M., and Riley E. Dunlap. 2011a. The politicization of climate change and polarization in the American public's views of global warming, 2001-2010. The Sociological Quarterly 52, no. 2 (2011a): 155-194.

- 2011b. Cool dudes: The denial of climate change among conservative white males in the United States. Global Environmental Change 21(4): 1163-1172.

Ontario Science Centre. 2018. "Public trust in science news is dangerously low, new Ontario Science Centre study reveals." Accessed March 2018. https://www.newswire.ca/news-releases/publictrust-in-science-news-is-dangerously-low-newontario-science-centre-study-reveals645328533.html

Oreskes, N. 2004. Science and public policy: What's proof got to do with it? Environmental Science and Policy, 7(5), 369-383. https://doi.org/10.1016/j.envsci.2004.06.002

Sarewitz, D. (2004). How science makes environmental controversies worse. Environmental Science and Policy, 7(5), 385-403. https://doi.org/10.1016/j.envsci.2004.06.001

Scruggs, Lyle, and Salil Benegal. 2012. Declining public concern about climate change: Can we blame the great recession? Global Environmental Change 22(2): 505-515.

Semenza, Jan C., David E. Hall, Daniel J. Wilson, Brian D. Bontempo, David J. Sailor, and Linda A. George. 2008. Public perception of climate change: voluntary mitigation and barriers to behavior change." American Journal of Preventive Medicine 35(5): 479-487.
Shapin, S. 1995. Here and Everywhere: Sociology of Scientific Knowledge. Annual Review of Sociology, 21(1), 289-321. https://doi.org/10.1146/annurev.soc.21.1.289 1998. Placing the View from Nowhere: Historical and Sociological Problems in the Location of Science. Transactions of the Institute of British Geographers, 23(1), 5-12. https://doi.org/10.1111/j.0020-2754.1998.00005.x Shapin, S., and Barnes, B. 1977. Science, Nature and Control: Interpreting Mechanics' Institutes. Social Studies of Science, 7(1), 31-74. https://doi.org/10.1177/030631277700700109

Statistics Canada. 2016. Gross domestic product, expenditure-based, by province and territory. Last modified November 09, 2016.

http://www.statcan.gc.ca/tables-tableaux/sumsom/101/cst01/econ15-eng.htm

Stehr, Nico. 2018. Climate Change: What Role for Sociology?. In Nico Stehr: Pioneer in the Theory of Society and Knowledge, pp. 343-354. Springer, Cham.

Stoddart, Mark CJ. 2007. Ideology, hegemony, discourse: A critical review of theories of knowledge and power." Social Thought and Research: 191-225.

van der Linden, Sander L., Anthony A. Leiserowitz, Geoffrey D. Feinberg, and Edward W. Maibach. 2015. The scientific consensus on climate change as a gateway belief: Experimental evidence. PloS one 10(2): $\mathrm{e} 0118489$.

van der Sluijs, Jeroen P., Rinie Van Est, and Monique Riphagen. 2010. Beyond consensus: reflections from a democratic perspective on the interaction between climate politics and science. Current Opinion in Environmental Sustainability 2(5): 409-415.

Way, Laura Anne. 2013. Canadian newspaper coverage of the Alberta oil sands: The intractability of neoliberalism. University of Alberta (Canada).

Weber, Elke U., and Paul C. Stern. 2011. Public understanding of climate change in the United States." American Psychologist 66(4): 315.

Whitmarsh, Lorraine. 2009. Behavioural responses to climate change: Asymmetry of intentions and impacts." Journal of Environmental Psychology 29(1): 13-23.

Wiggins, Sally. 2016. Discursive psychology: Theory, method and applications. Sage. 